- Children, the elderly, low-income people and farmworker families, right, may be particularly vulnerable to environmental toxicants, such as pesticides.

Young children and elderly people are at great risk of poor nutrition. In a study of low- and highincome young children, we found that a large percentage of both groups, between $24 \%$ and $13 \%$, had low intakes of calcium, iron and copper. Interestingly, the high-income children had greater deficiencies of several nutrients than the low-income children. Another study showed that many senior citizens consume diets providing less than two-thirds of the recommended dietary intakes of some essential vitamins and minerals. Further, animal experiments and human studies indicate that nutritional status can influence an individual's susceptibility to environmental toxicants including air pollutants, food contaminants, heavy metals and pesticides. For example, dietary antioxidants are known to aid in the metabolism of organophosphate pesticides; but low-income farmworkers and their children, who are at greater risk of pesticide exposure, often do not consume enough fruits and vegetables with these important nutrients. Likewise, children and adults with iron-deficiency anemia absorb more lead from their environments than those with adequate iron stores. Conversely, good nutrition at all life stages can decrease susceptibility to adverse effects of toxicants. Additional studies on the interactions between diet and chemical exposure in humans will be needed in the future.

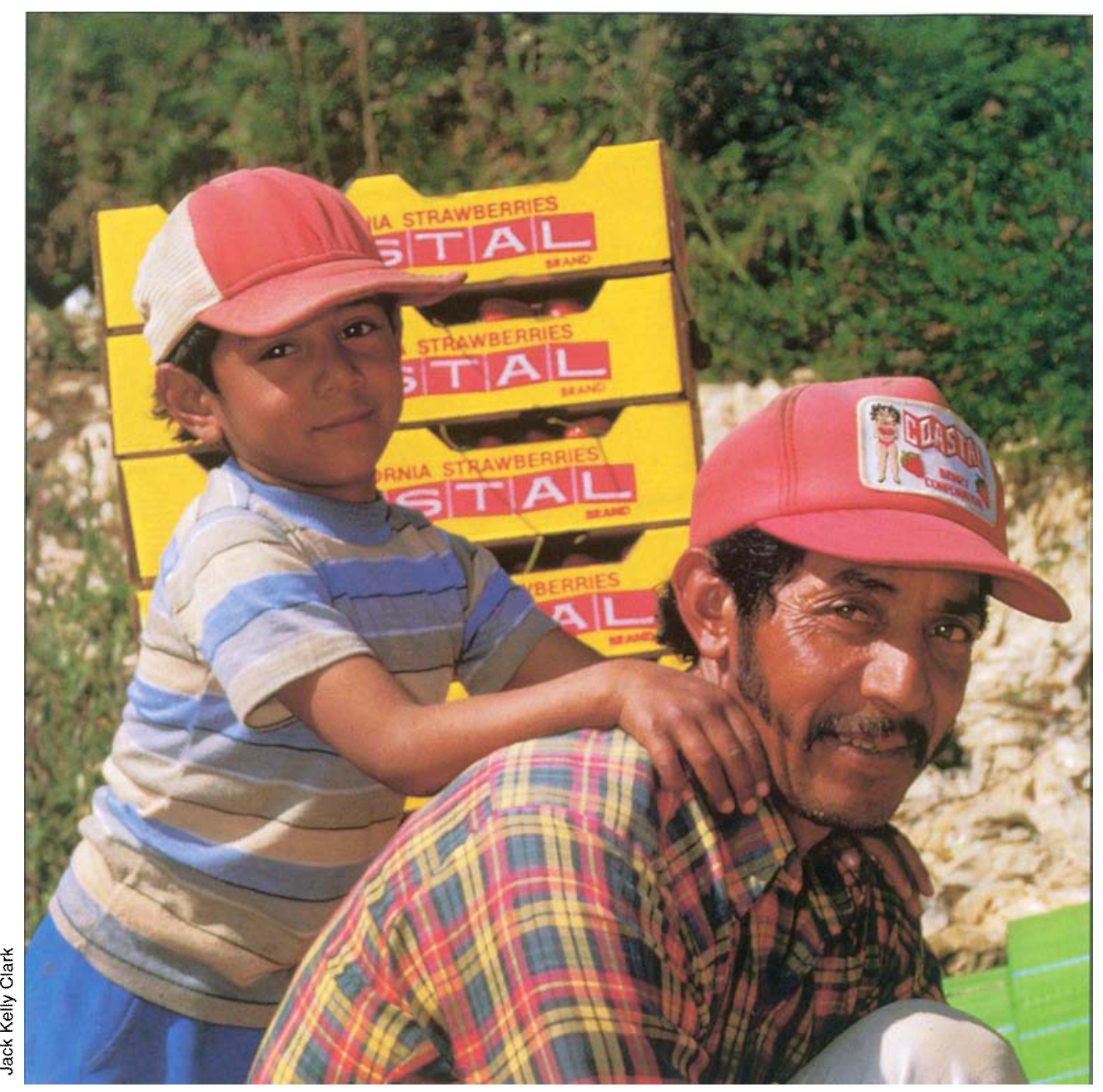

\title{
Nutrition may influence toxicant susceptibility of children and elderly
}

\author{
Sheri Zidenberg-Cherr \\ $\square$ Michelle R. Neyman $\square$ Krista Fechner \\ Jeanette Sutherlin Margaret Johns \ Cathi Lamp \\ Constance Garrett $\square$ Carl L. Keen
}

$\mathrm{D}$ uring the past decade, awareness has increased of the critical role that nutrition plays in modulating an individual's susceptibility to environmental toxicants, including air pollutants, food contaminants such as aflatoxin, heavy metals and pesticides. This interest is based on results from both animal experiments and human studies (Sinclair 2000; Bannerjee 1999;
Oteiza et al. 1999; Hackman and Hurley 1983).

This area of research has received particular attention from scientists as it relates to the influence of nutritional status on women's response to toxicants that can cause birth defects (Keen et al. 1997). Indeed, during the past few years, a consensus has been emerging that consuming essential nu- 


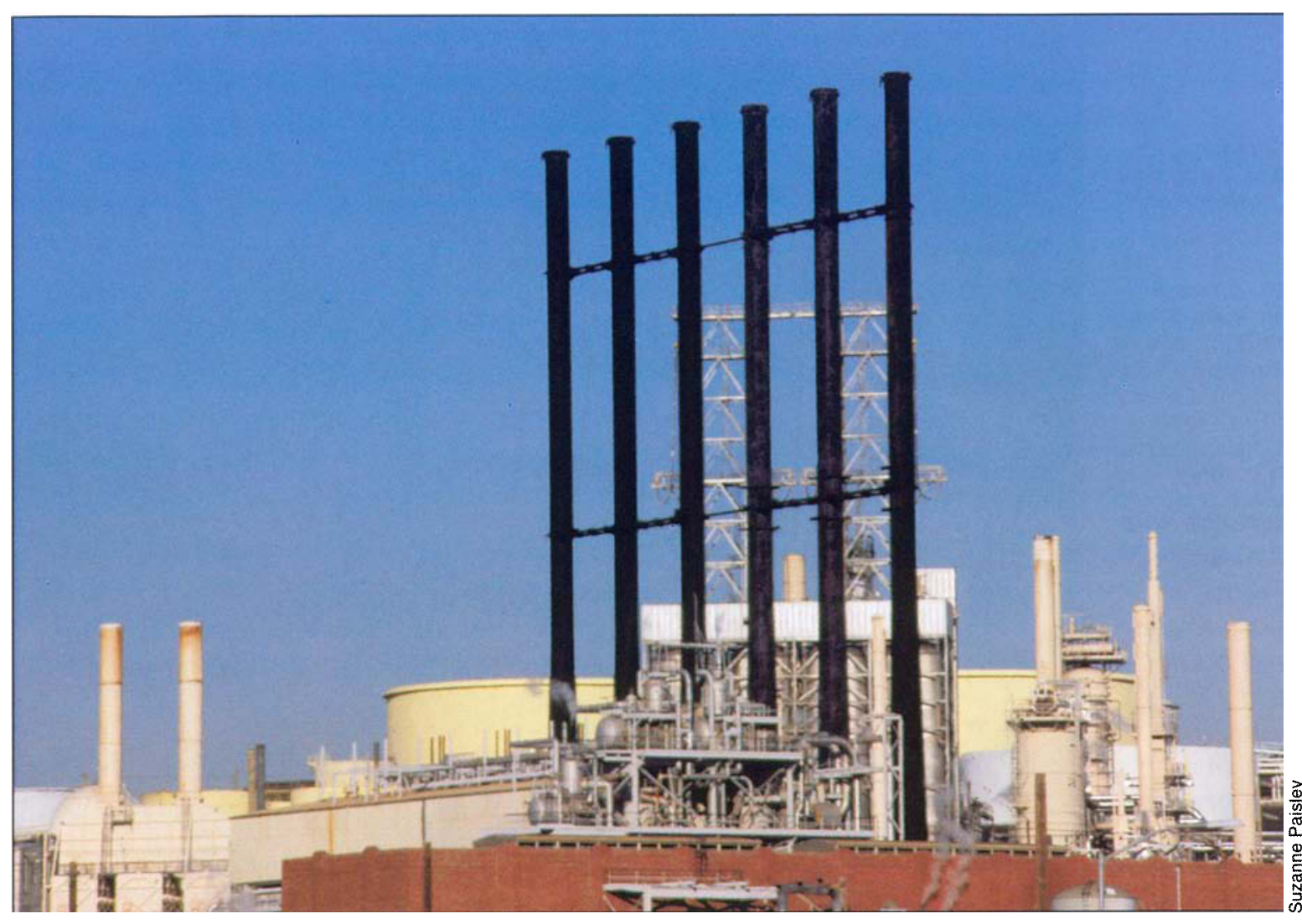

result of marked improvements in food production, storage, delivery and availability during the past 50 years. Improvements in nutritional status have also been a consequence of aggressive food fortification programs, such as the augmentation of salt with iodine, milk with vitamin $D$ and cereals with many of the B vitamins. However, while the nutritional status of most individuals is good, it remains suboptimal for a significant proportion of the U.S. population.

Recently, our research group at UC Davis studied the dietary patterns of children ages 1 through 4

Susceptibility to toxicants such as air pollution, above, is influenced by numerous factors including the person's nutritional status, genetics, immune system and general health.

trients during pregnancy - either through fortified foods or supplements - may provide protection against the effects of certain reproductive toxicants. For example, adding folic acid to a pregnant woman's diet may reduce the teratogenicity of methanol, which is metabolized in part via folate-dependent pathways (Fu et al. 1996; Sakanashi et al. 1996).

In the past, most toxicological models have been based on healthy adult males rather than groups considered vulnerable, such as children, the elderly, economically disadvantaged people or farmworkers. In particular, there is a paucity of information concerning the extent to which marginal nutritional deficiencies can alter the sensitivity of young children to environmental toxicants. A 1993 National Research Council report, Pesticides in the Diets of Infants and Children, emphasized the critical need for more information on children's exposure to pesticides and the factors that influence sensitivities to them.

Due to behavioral and physiological factors, children can be more sensi- tive than adults to pesticides. Because their nervous systems are still developing, children may be particularly sensitive to organophosphate and carbamate pesticides, widely used agricultural chemicals that are nervoussystem toxins. In addition, differences in their ability to activate, detoxify and excrete chemicals may put children at an increased risk for adverse effects from pesticide exposure.

While this paper focuses on nutritionaltoxicant interactions among children and senior citizens, multiple factors can influence an individual's response to various toxicants, including their genetic constitution, integrity of immune system, the presence or absence of diseases and the physical environment. While not discussed here, these factors must be fully considered when formulating public policies and risk assessment analysis.

\section{Children's diets low in minerals}

In developed countries such as the United States, severe nutritional deficiencies are rarely observed in healthy populations. The overall good nutritional status of our population is the in California. We selected two sets of subjects: a largely Hispanic low-income group (income less than $150 \%$ of the poverty level, which is $\$ 17,050$ for a family of four; $n=151$ ) and a largely white, higher-income group $(>\$ 50,000)$ $(n=64)$. The low-income group was recruited from clinics of California child health and disability prevention program providers in Fresno, San Bernardino and Tulare counties. The high-income group was recruited from a private physician's practice in Sonoma County (Fechner et al. 1996).

We assessed the children's dietary intakes through in-person multiple dietary recalls and a food frequency questionnaire with their parents. Comparison of nutrient intakes to the recommended levels showed that many children in both income groups consumed inadequate calcium, iron, zinc and copper. Zinc intakes were well below the National Academy of Sciences' Food and Nutrition Board (FNB) recommended dietary allowance (RDA) for a significant proportion of the children studied. Interestingly, there was a higher frequency of low intakes among the high-income children than the low-income children. Zinc intakes 
were less than two-thirds of the RDA in $76 \%$ of the high-income children, compared to $60 \%$ of the low-income children. This was due in part to lower intakes of meat among the high-income children, because their parents perceived meat-heavy diets as unhealthy and a source of excess dietary fat. $\mathrm{Nu}$ tritionists and public-health professionals often encounter such difficulties as they try to define "optimal" diets. Specifically, a diet that is low in fat (presumably of value with respect to the prevention of cardiovascular disease) may also be low in important essential micronutrients.

Furthermore, $24 \%, 22 \%$ and $20 \%$ of the low-income children had intakes of calcium, iron and copper, respectively, that were less than two-thirds of the FNB's recommended levels. Similarly, for the high-income group, $19 \%, 13 \%$ and $16 \%$ of the children had low intakes of calcium, iron and copper, respectively. Therefore, a large proportion of children may be at risk for essential micronutrient deficiencies independent of their socioeconomic status.

Assuming that the FNB's recommended intake values are appropriate, essential nutrient intakes for many individuals are clearly inadequate. There is a remarkable dearth of information concerning how these marginal intakes influence an individual's ability to either respond to, or recover from, exposure to toxic xenobiotics (foreign chemicals) or other natural stressors such as ozone, pollutants and several medications. The need for such studies is particularly acute for young children, given their high risk for nutrient deficiencies and their vulnerability to environmental contaminants.

Biochemical assessments can determine if low intakes of certain micronutrients are associated with abnormal blood biochemistry. In the same study, mean hemoglobin, hematocrit and plasma ferritin values were similar among the high- and low-income children (table 1). However, $17 \%$ of the children had hemoglobin and hematocrit values that were below the U.S. Centers for Disease Control and Prevention (CDC) cutoffs. Using a cutoff of 10 micrograms per liter for ferritin, $8 \%$ of the children studied were classified as at risk for low iron stores. Mean plasma iron, zinc and copper concentrations were lower in the highincome group than in the low-income group. Hypozincemia - defined as a plasma zinc concentration less than 10.4 micromolars - was observed in $46 \%$ of the high-income and $13 \%$ of the low-income children. The data demonstrate that the marginal dietary intakes of zinc and iron observed in the children are functionally significant.

Blood lead concentrations, also determined for the children in this study, ranged from less than 5 to 14 micrograms per deciliter (Zidenberg-Cherr et al. 1996). Encouragingly, only $2 \%$ of the children in the high-income group had blood lead in excess of $5 \mu \mathrm{g} / \mathrm{dL}$, but $25 \%$ of the children in the lowincome group had values exceeding this level. While only two of the children studied had blood lead levels

\begin{tabular}{|c|c|c|}
\hline \multicolumn{3}{|c|}{$\begin{array}{l}\text { TABLE 1. Mean levels of biochemical status indicators for iron, zinc and copper } \\
\text { and percentage of children falling below standard cutoffs, by income level }\end{array}$} \\
\hline Status measure & Lower income & Higher income \\
\hline $\begin{array}{l}\text { Ferritin }(\mu \mathrm{g} / \mathrm{L}) \\
\text { Hemoglobin }(\mathrm{g} / \mathrm{L}) \\
\text { Hematocrit }(\%) \\
\text { Plasma iron }(\mu \mathrm{M}) \\
\text { Plasma zinc }(\mu \mathrm{M}) \\
\text { Plasma copper }(\mu \mathrm{M})\end{array}$ & $\begin{array}{r}27.7+16.7 \\
117.1+8.3 \\
34.6+2.3 \\
20.0+7.6 \\
12.7+2.1 \\
21.0+3.1\end{array}$ & $\begin{array}{l}24.3+15.0 \\
119.4+7.4 \\
34.9+2.2 \\
16.5+6.6^{\star} \\
10.5+2.4 \dagger \\
19.3+3.0 \ddagger\end{array}$ \\
\hline $\begin{array}{l}\text { Low hemoglobin/hematocrit§ } \\
\text { Low ferritinๆ } \\
\text { Low plasma zinc\# }\end{array}$ & $\begin{array}{r}18.9 \\
8.9 \\
12.8\end{array}$ & $\begin{array}{c}13.6 \\
6.5 \\
45.7 \dagger\end{array}$ \\
\hline
\end{tabular}

"Mean or proportion is significantly different by income $(P<0.05)$

†Mean or proportion is significantly different by income $(P<0.001)$

$¥$ Mean or proportion is significantly different by income $(P<0.01)$

$\S$ Hemoglobin less than $110 \mathrm{~g} / \mathrm{L}$ for age 1 year and less than $112 \mathrm{~g} / \mathrm{L}$ for age 2-4 years; hematocrit less than

$33 \%$ for age 1 year and less than $34 \%$ for age $2-4$ years.

Ferritin less than $10 \mu \mathrm{g} / \mathrm{L}$

\#Plasma zinc less than $10.4 \mathrm{uM}$

Regrettably, marginal nutritional deficiencies still occur in wide segments of our society. Based on extensive experimental data, we know that deficiencies can result in an increased risk for a number of toxicants.

that exceeded the current $\mathrm{CDC}$ action level of $10 \mu \mathrm{g} / \mathrm{dL}$, the fact that the larger proportion of children in the low-income group had blood lead levels between 5 and $10 \mu \mathrm{g} / \mathrm{dL}$ is of concern; it demonstrates that children in this group have a greater exposure to lead compared to higher socioeconomic groups.

\section{Nutritional status of elderly}

In addition to children, other age groups such as the elderly can also be characterized by inadequate diets (Roe 1992; Cohen and Ralston 1993;

Dickenson et al. 1993; Koughan and Atkinson 1993; Neyman et al. 1998). Using multiple 24-hour recalls and a culturally sensitive food-frequency questionnaire, we examined the dietary intakes of Hispanic senior citizens. We recruited 80 Hispanic men and women ages 60 to 93 years who were either participating or not participating in congregate-site meal programs from senior centers and other senior organizations in Kern and Fresno counties. The results showed that a large proportion of seniors consume diets that provide less than twothirds of the FNB's recommended in-

\begin{tabular}{lc}
$\begin{array}{c}\text { TABLE 2. Percent of Hispanic seniors with } \\
\text { intakes less than } 2 / 3 \text { of NAS Food and } \\
\text { Nutrition Board's recommended levels }\end{array}$ \\
\hline \hline Nutrient & $\%$ \\
\hline Folate $(\mu \mathrm{g})$ & 19 \\
B6 $(\mathrm{mg})$ & 36 \\
B12 $(\mu \mathrm{g})$ & 11 \\
Vitamin A ( $\mu \mathrm{g}$ RE) & 28 \\
C (mg) & 24 \\
E (mg TE) & 55 \\
Calcium (mg) & 38 \\
Iron (mg) & 9 \\
Magnesium (mg) & 38 \\
Zinc (mg) & 60
\end{tabular}



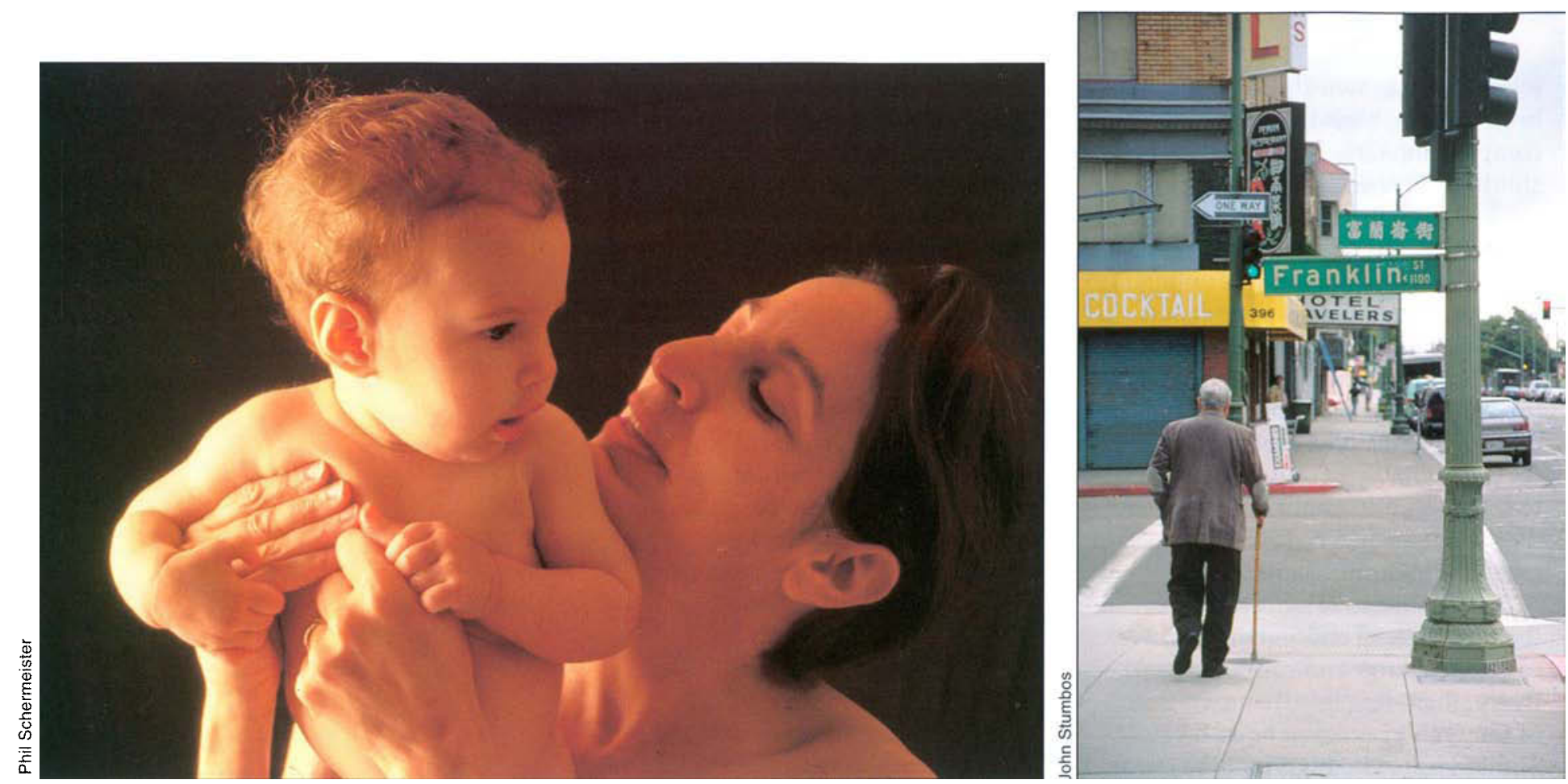

During the past 50 years, improvements in overall nutrition in the United States have been dramatic. But in the authors' research, children at both high and low socioeconomic levels were not getting enough calcium, iron, zinc and copper. Likewise, elderly Hispanic men consumed far below the National Academy of Sciences' recommended levels for many nutrients.

takes for select nutrients (table 2). These individuals may also have a heightened sensitivity to certain environmental toxicants.

Marginal nutritional deficiencies can be present in particular population groups at relatively high frequencies. A critical concern is the extent to which these deficiencies influence an individual's ability to respond to environmental toxicants. To explore this issue further, we consider the influence of nutrition on how people's bodies react to two classes of environmental toxicants, pesticides and heavy metals.

\section{Metabolism of foreign chemicals}

The metabolism of many pesticides occurs in humans and experimental animals primarily through the actions of detoxification enzymes including cytochrome p-450 and other factors related to the mixed-function oxidases (Guengerich 1995). Inadequate activity of this system may result in a low rate of detoxification for many pesticides. Because these enzymes are influenced by nutritional status, it is reasonable to suggest that the ability of an individual to "handle" a given level of a pesticide will be compromised by poor nutrition. An individual's susceptibil- ity to pesticide toxicity is therefore determined, in part, by his or her nutritional status (Matsumura 1995).

Diet can have a significant influence on the mixed-function oxidase enzyme system. While the majority of studies to date in this area have been conducted on experimental animals, it is reasonable to suggest that similar effects occur in humans. Additional studies on the interactive effects of nutritional deficiencies on pesticide metabolism are urgently needed.

While several reports suggest that exposure to free radicals plays a role in the toxicity of many organophosphate pesticides, several additional reports also suggest that antioxidants in food and vitamins may protect against the damage induced by their metabolism. For example, several investigators have noted decreased adverse effects associated with organophosphates when vitamins $C$ and $E$ are administered to laboratory animals. Several studies have reported that vitamin $\mathrm{E}$ is highly effective in protecting against lymphocyte damage, DNA single-strand breaks, and inhibition of organophosphate- induced lipid peroxidation (Matsumura 1995; Stevenson et al. 1995). This is of physiological significance because there may be reduced availability of the antioxidant glutathione due to its use in pesticide metabolism; thus there may be an increased need for dietary antioxidants such as vitamins $\mathrm{C}$ and $\mathrm{E}$ and beta-carotene in children with excessive exposure to pesticides.

The potential increased need for antioxidants may present a problem given that the concentration of antioxidant nutrients is highest in fresh fruits and vegetables, which are often consumed in relatively small quantities by individuals from all socioeconomic groups. Indeed, the intake of several dietary antioxidants by children and senior citizens is often well below the current recommended levels, even before factoring in an increased need for them among those exposed to high levels of oxidant-producing chemicals.

Migrant farmworkers are believed to be at a particularly high risk for nutrition-related disorders because of their low socioeconomic status, poor living environments and migratory lifestyle (Slesinger 1992). Numerous health agencies have suggested that migratory farmworkers and their families have high rates of malnutrition, which makes their children espe- 
cially vulnerable to adverse health conditions such as cancer and respiratory illnesses. Environmental exposure to pesticides superimposed upon an already compromised nutritional status may make these children particularly susceptible to the toxic effects of pesticides.

\section{Risk of lead poisoning}

Childhood lead poisoning continues to be a major health hazard in the United States despite impressive gains in reducing environmental lead levels during the past 20 years (Crocetti et al. 1990). Lead exposure
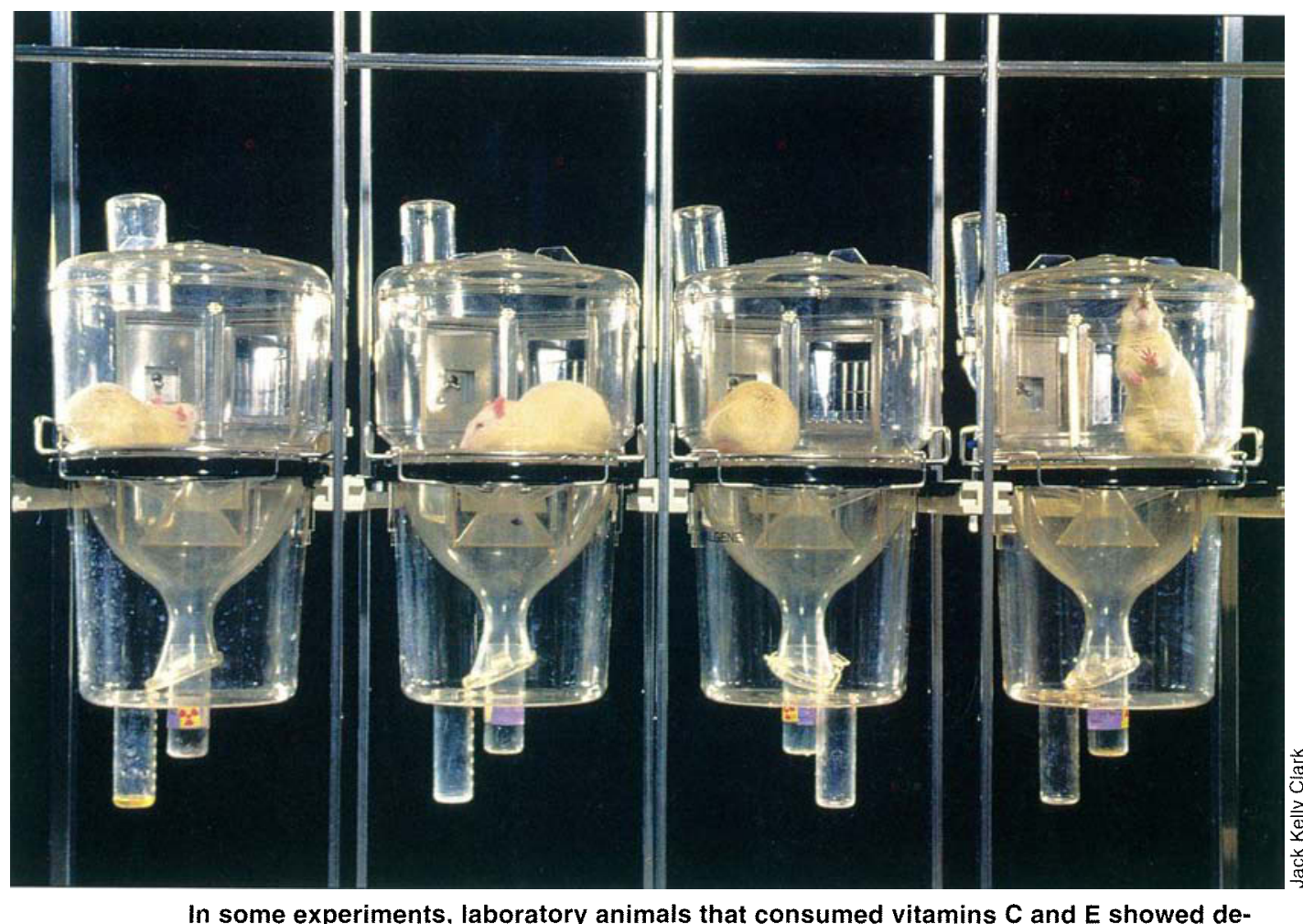

can result in serious long-term effects in children such as lethargy, behavior abnormalities and low-grade learning problems, even when no overt illness or symptoms are noticeable. Importantly, when treated early many of the effects are reversible.

Lead absorption from the gastrointestinal tract can be greatly influenced by diet composition (Mahaffey 1990; Barltrop and Khoo 1975). Animal studies have shown that diets low in calcium or iron, or high in fat, enhance lead absorption. Similarly, interactions between a number of trace elements, such as iron and calcium, and lead in humans have been identified (Miller et al. 1990). Considerable attention has been paid to studies investigating the influence of iron status on lead toxicity since iron deficiency is a common nutritional problem in young children. The risk of anemia among California children is an estimated $18 \%$, according to CDC. Significantly, lead toxicity is more common in children with anemia than in healthy, nonanemic children (Wasserman et al. 1992). Children and adults with iron-deficiency anemia absorb more lead from their environments than those with adequate iron stores. A low dietary intake of zinc may also increase an individual's susceptibility to lead toxicity. The interaction of zinc and lead deserves

more investigation, since women and children in populations that have high risk of lead exposure often have marginal zinc intakes.

Taken together, the studies cited demonstrate the existence of interactions between lead and several nutrients. A large body of evidence suggests that when a child's dietary status is suboptimal, there is an increased risk for lead toxicity. A key step in the prevention of lead toxicity will be to improve the diets of high-risk populations.

\section{Future in focus: Improving nutrition}

Regrettably, marginal nutritional deficiencies still occur in wide segments of our society. Based on extensive experimental data, we know that deficiencies can result in increased risks for a number of toxicants. This occurs because population groups that are more likely to develop nutritional deficiencies also have a greater chance of exposure to toxicants. It is imperative that regulatory agencies at the federal, state and local levels consider factors such as nutritional status in their risk assessment calculations.

A long-term societal goal will be to identify means by which we can im- prove the nutritional status of the general population and eliminate poor nutrition as a risk factor. As demonstrated by our investigations of high-income children, attaining optimal nutritional status can be difficult even when parents feed their children what they perceive to be healthy diets. The elderly comprise a growing proportion of the nation's population and health-care resources, yet their special needs in terms of protection from exposure to environmental toxicants and provision of adequate diets are just beginning to be understood (Rogers 1997).

Good nutrition at all life stages can decrease susceptibility to adverse effects of toxicants; therefore, nutrition must be incorporated into models used for risk assessment of toxicants (Rogers 1997). Intensive efforts must be made to identify the optimal intakes of nutrients under specific environmental conditions. Once optimal diets are identified, comprehensive strategies must be developed to ensure that all segments of society can achieve these diets.

Recently there has been an increased emphasis on the investigation of toxicant-nutrient interactions. This 


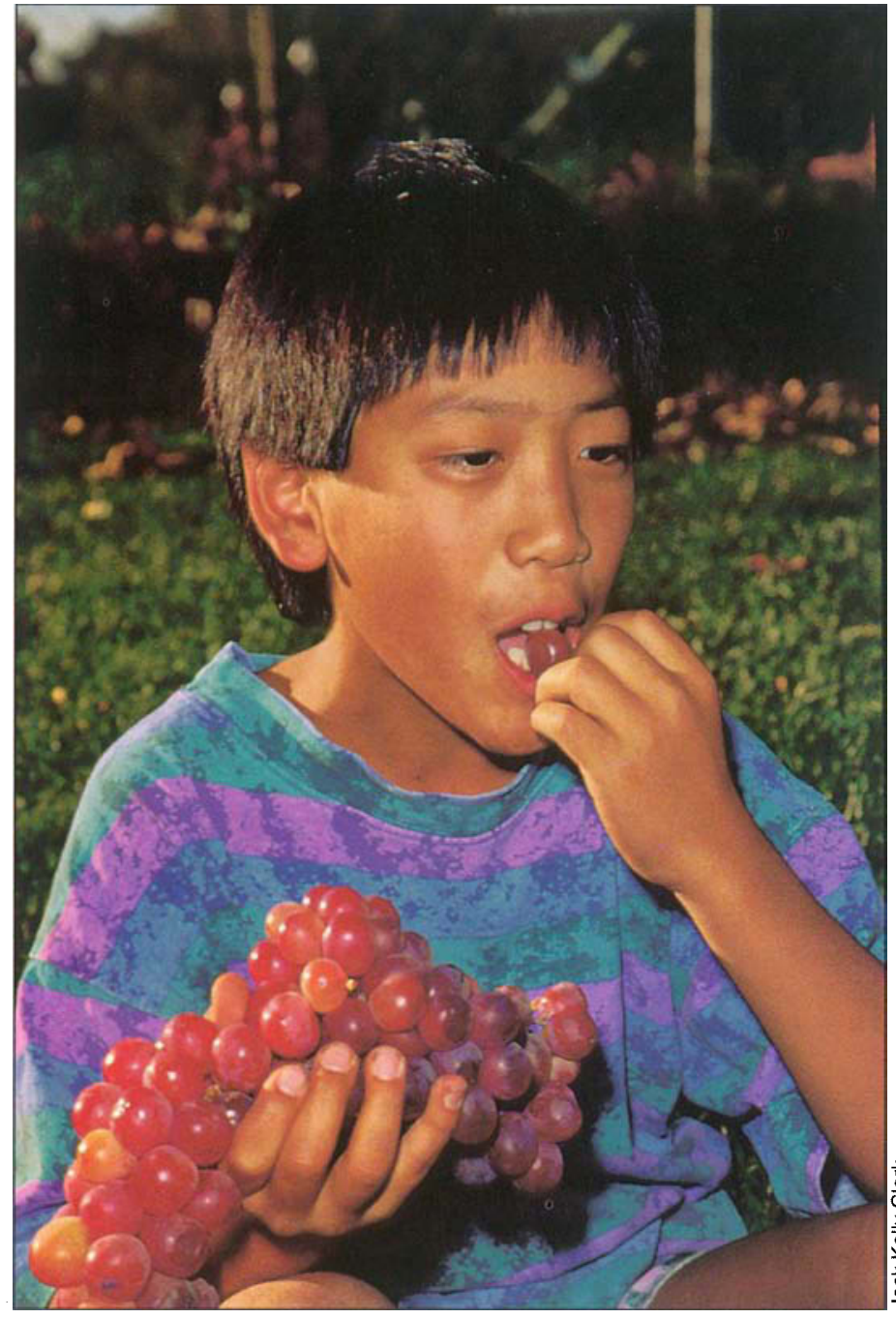

Even chilaren or parents wno delieve they are providing a healthy diet may not attain optimal nutrition. The authors found that children of higher socioeconomic status did not necessarily have better diets than low-income children.

is true for university researchers as well as for government agencies such as the U.S. Environmental Protection Agency, CDC and NIH. It is reasonable to speculate that in the near future, committees will likely be asked to construct dietary recommendations that are applicable to specific at-risk populations. For example, if high intakes of dietary antioxidants reduce an individual's risk for heavy metal or pesticide poisoning, it might be prudent to suggest an increased vitamin $\mathrm{E}$ or vitamin $C$ requirement for exposed populations. This type of logic has already been advanced for vitamin $C$ in that the recommended intake for this nutrient is increased for individuals who smoke.

In a similar vein, if subtle differences in the dietary intake of a nutrient markedly modulates the risk for some disease (or the susceptibility to various toxicants), it suggests that there should be an increased emphasis on the study of the nutritional status of highrisk populations. If such studies in turn demonstrate that certain populations have a higher than normal risk for suboptimal diets, new intervention plans aimed at correcting these deficits will be needed. For example, if it is dem尊 onstrated that children in migrant farmworker families are at greater risk of deficiencies of antioxidants such as vitamin E, special efforts could be made to increase vitamin $\mathrm{E}$ intake of those children. However, without adequate funds to conduct controlled studies, we will not have the answers necessary to make such recommendations. Such efforts could include more focused intervention programs that incorporate supplementation with vitamin $\mathrm{E}$ and comprehensive nutrition education programs to ensure optimal intake of the nutrients at risk.

Complicating matters is the growing awareness of the critical role that genetics can play in modulating an individual's response to toxicants, as well as to nutritional deficiencies. It will be difficult in the future to make broad recommendations for entire population groups. In place of general recommendations, there will be an increasing demand by the public for individualized dietary recommendations. The consideration of the work and living environment of the individual is bound to play an increasing role in the determination of an individual's "recommendations."

The University has an obligation to its constituency to make them aware of ongoing research in this area. An efficient and effective way of reaching the greatest number of people is through the delivery of information through educators who are trained in and understand, the scientific method. A few years ago nutrition professionals often stated that "you can get all the nutrients you need from food," but now scientists must accept newly acquired knowledge that in some cases, diets can be optimized through food fortification and/or supplementation. Finally, we must begin dealing with the reality that people's requirements can differ significantly for certain nutrients, and we will have to develop new education and intervention programs that address this reality.

S. Zidenberg-Cherr is Nutrition Science Specialist, Department of Nutrition, UC Davis; M.R. Neyman is Assistant Professor, California State University, Chico; $K$. Fechner is Technical Writer, International Microcomputer Software; J. Sutherlin, $M$. Johns, C. Lamp, C. Garrett are Nutrition, Family and Consumer Sciences Advisors, UC Cooperative Extension; and C.L. Keen is Chair and Professor, Department of $\mathrm{Nu}^{-}$ trition, UC Davis.

\section{References}

Bannerjee BD. 1999. The influence of various factors on immune toxicity assessment of pesticide chemicals. Tox Letters 107:21-31

Barltrop D, Khoo HE. 1975. The influence of nutritional factors on lead absorption. Postgrad Med J 51:795-800.

Cohen NL, Ralston PA. 1993. Factors related to dietary quality in elderly blacks. FASEB J 7:A202.

Crocetti AF, Mushak P, Schwartz J. 1990. Determination of numbers of lead-exposed U.S. children by areas of the United States: An integrated summary of a report to the U.S. Congress on childhood lead poisoning. Env Health Perspectives 89:109-20.

Dickenson A, Block G, Russek-Cohen E. 1993. Serum vitamin C levels in adult supplement users and nonusers in NHANES II multiple analysis incorporation of other dietary and demographic variables. FASEB J 7:A295. 


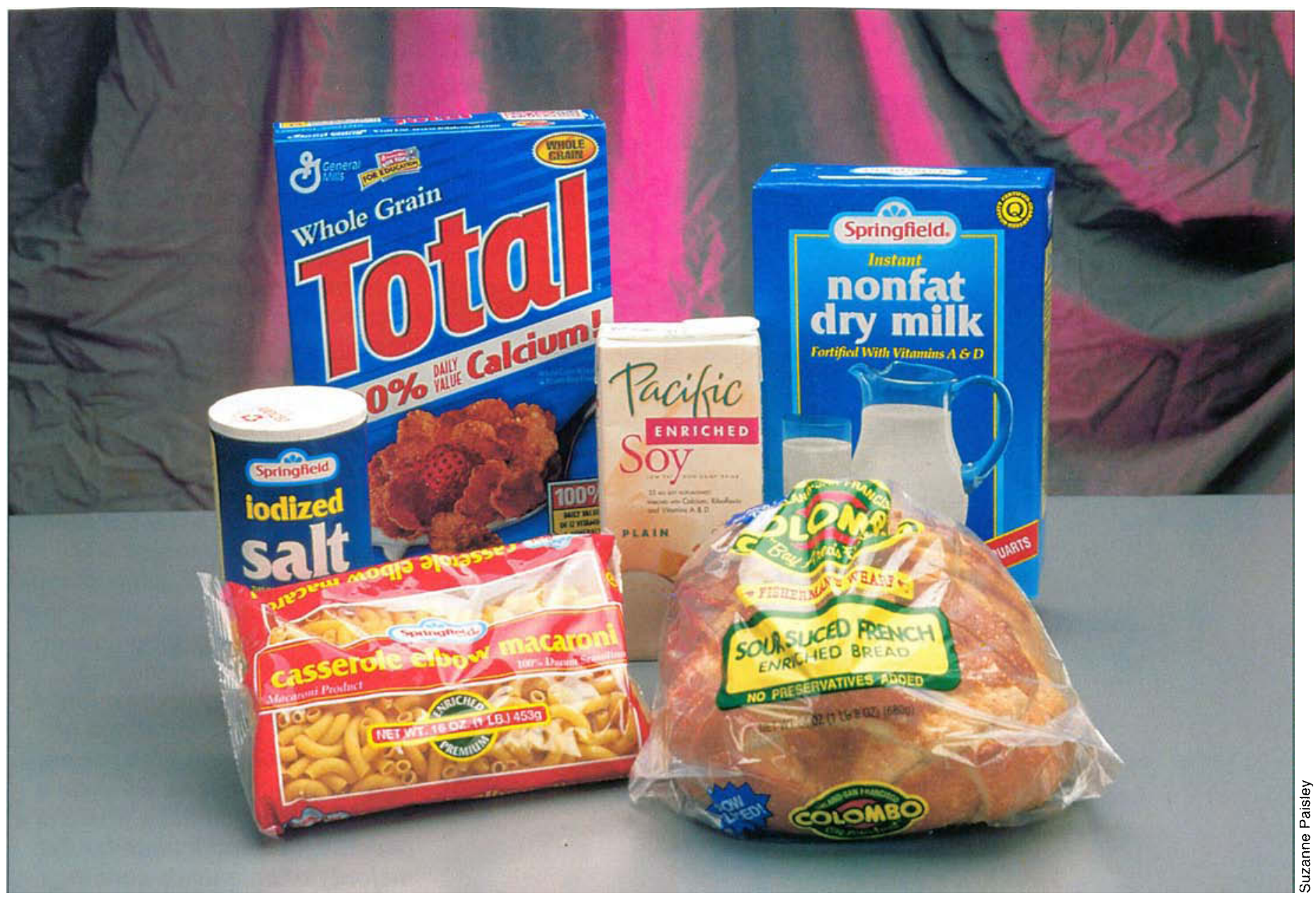

While nutrition professionals have often said "you can get all the nutrients you need from food," new research is showing that this may not always be true. In the future, individualized dietary recommendations may be necessary, as well as greater reliance on food fortification, above, and dietary supplements for certain populations.

Fechner K, Finnegan C. Garrett C, et al. 1996. Dietary intake in children at low and high risk for lead poisoning. FASEB J 8:A481.

Fu SS, Sakanashi TM, Rogers JM, et al. 1996. Influence of dietary folic acid on the developmental toxicity of methanol and the frequency of chromosomal breakage in the CD1 mouse. Repro Toxicol 10:455-63

Guengerich FP. 1995. Influence of nutrients and other dietary materials on cyto. chrome P-450 enzymes. Am J Clin Nutr 61:651S-8S

Hackman RM, Hurley LS. 1983. Interaction of dietary zinc, genetic strain and acetazolamide in teratogenesis in mice. Teratology 28:355-68

Keen CL, Taubeneck MW, ZidenbergCherr S, et al. 1997. Toxicant exposure and trace element metabolism in pregnancy. Env Toxicol and Pharmacol 4:301-8.

Koughan N, Atkinson C. 1993. Nutrition screening initiative and the Louisiana food for seniors experience. J LA State Med Soc17:432-41.

Mahaffey KR. 1990. Environmental lead toxicity: Nutrition as a component of intervention. Env Health Perspectives 89:75-8.
Matsumura F. 1995. Mechanism of action of dioxin-type chemicals, pesticides and other xenobiotics affecting nutritional indexes. Am $J$ Clin Nutr 61:695S-701S.

Miller GD, Massaro TF, Massaro EJ. 1990. Interactions between lead and essential elements: A review. Neurotoxicology 11(1):99-119.

National Research Council. 1993. Pesticides in the Diets of Infants and Children. Washington, DC: National Academy Press. $386 \mathrm{p}$.

Neyman MR, Block $G$, Johns $M$, et al 1998. Effect of participation in congregatesite meal programs on the energy and nutrient intakes of Hispanic seniors. JADA 98:1460-2.

Oteiza PI, Adonaylo VN, Keen CL. 1999. Cadmium-induced testes oxidative damage in rats can be influenced by dietary zinc intake. Toxicology 137:13-22.

Roe DA. 1992. The nutritional status of the elderly. In: Roe DA, Copeland L (eds.) Geriatric Nutrition. Englewood Cliffs, NJ: Prentice Hall. p 57-67.

Rogers JM. 1997. Life stage and its impact on risk of environmentally induced ad- verse effects: Introduction. Env Toxicol and Pharmacol 4:299-300

Sakanashi TM, Rogers JM, Fu SS, et al. 1996. Influence of maternal folate status on the developmental toxicity of methanol in the CD-1 mouse. Teratology 54:198-206.

Sinclair S. 2000. Male infertility: Nutritional and environmental considerations. Alt Med Rev 5:28-38

Slesinger DP. 1992. Health status and needs of migrant farmworkers in the United States: A literature review. J Rural Health 8:227-34

Stevenson DE, Kehrer JP, Kolaja KL, et al. 1995. Effect of dietary antioxidants on dieldrin-induced hepatocotoxicity in mice. Tox Letters 75:177-83.

Wasserman G, Graziano JH, Factor-Litvak P. 1992. Independent effects of lead exposure and iron deficiency anemia on developmental outcome at age 2 years. J Pediatr 121:695-703

Zidenberg-Cherr S, Fechner K, Garrett C, et al. 1996. Trace element status in children at low and high risk for lead poisoning. FASEB J 8:A785. 